\title{
Fibrodysplasia ossificans progressiva: a case report
}

\author{
Richard O. Baidoo and Makafui S. Dayie \\ Ghana Med J 2016; 50(4): 248-250 DOI http://x.doi.org/10.4314/gmj.v50i4.8
}

\section{Department of Surgery, Cape Coast Teaching Hospital, Cape Coast, Ghana}

Corresponding author: Dr Richard O. Baidoo

Conflict of interest: None declared

\section{SUMMARY}

Fibrodysplasia Ossificans Progressiva is a rare debilitating disorder of the musculoskeletal system affecting one in two million individuals. It is characterized by progressive extraskeletal ossification of soft tissues resulting in the original skeleton being encased in unyielding new bone leading to disability and ultimately death from cardiorespiratory failure. The present case brings to light the delays and potential pitfalls in diagnosis as a result of the rarity of the condition.

Keywords: Fibrodysplasia Ossificans Progressiva, ACVR1, Extra-skeletal ossification, Hallux valgus, Steroids.

\section{INTRODUCTION}

Fibrodysplasia Ossificans Progressiva (Munchmeyer's disease, stoneman's disease, Myositis Ossificans Progressiva) first described by Guy Patin in $1692,{ }^{1,2}$ is a rare progressively disabling disease characterized by congenital malformations of the great toes and extraskeletal bone formation that gradually encases the original skeleton resulting in restriction of movement and eventual immobility and mortality from cardiorespiratory complications around the fourth decade of life. ${ }^{1,3}$

It is extremely rare with an incidence of one in two million individuals occurring without bias to gender, race or ethnicity. ${ }^{4}$ It is an autosomal dominant disorder with most patients having a spontaneous new mutation of a bone morphogenic protein type 1 receptor (ACVR1) which results in activation of osteogenesis in ectopic sites without ligand binding. ${ }^{5,6}$ Familial cases have also been reported.

Individuals are born usually following an uneventful gestation but the great toe abnormalities are almost invariably present at birth. ${ }^{2,4}$ These include hallux valgus, shortened great toes and sharpening of the first metatarsal bone. ${ }^{8}$ In the first decade of life, intermittent episodes of painful soft tissue swellings occur which progress to become the hard, bony lesions that characterize the disease. Biopsy reveals endochondral bone formation in ectopic sites but predictably leads to worsening of the condition with explosive new bone formation and calcification as has been seen in individuals who have inadvertently had a biopsy.
Early diagnosis slows progression of the disease and crucially helps to avoid biopsies or procedures that result in florid exacerbations. ${ }^{9}$

\section{CASE REPORT}

A nine-year-old boy presented with a five year history of multiple neck and back swellings. He was the product of a normal term pregnancy with non-consanguineous parents and no other member of his extended family had similar swellings.

Clinical records reveal that at the age of four, he was diagnosed with probable spinal tuberculosis but didn't undergo treatment because there wasn't additional supporting clinical or laboratory evidence.

At the age of six, he was managed as a case of multiple exostoses and was treated non-operatively but was subsequently lost to follow-up.

He re-presented at the age of nine with neck swelling, stiffness, pain and numerous bony swellings over the occiput, the posterior neck, parascapular and thoracolumbar paraspinal regions.(Figures $1 \mathrm{~A}$ and 1B) Further examination revealed bilateral big toe malformations (hallux valgus) that had been present since birth but wasn't of concern to the patient nor his parents.(Figure 3) Radiographs revealed extra skeletal ossification of the soft tissues of the posterior neck, para scapularthoracolumbar regions and confirmed bilateral hallux valgus deformities.(Figures 2 and 4 ) 


\section{Case Report}

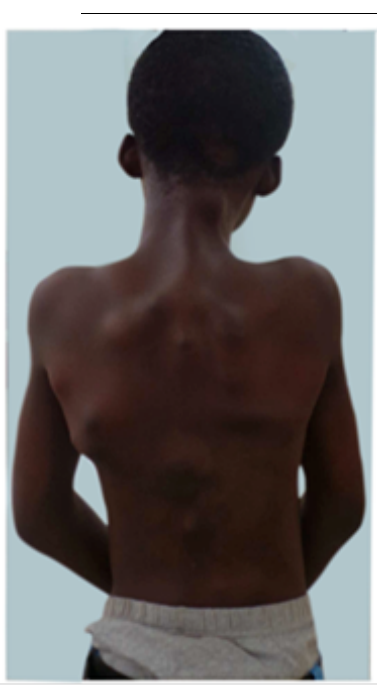

Figure 1A Bony swellings over back and neck

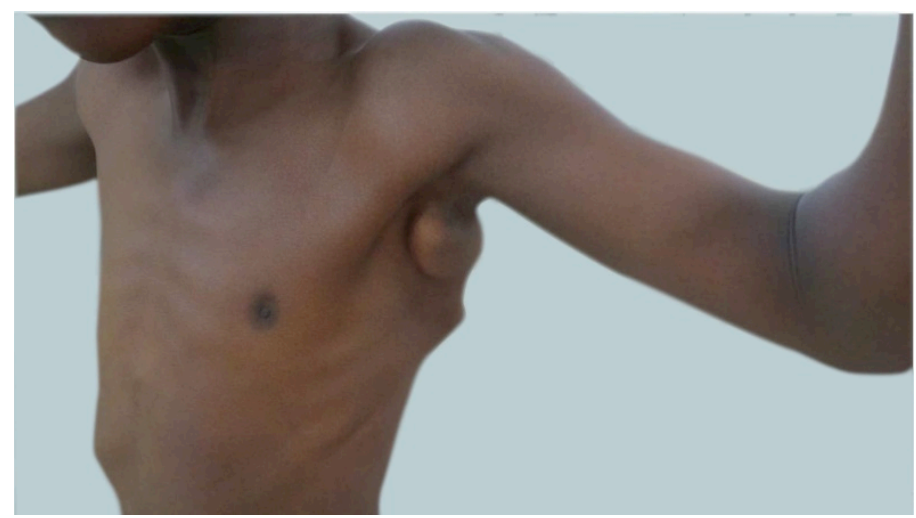

Figure 1B Similar swellings in thoracic region

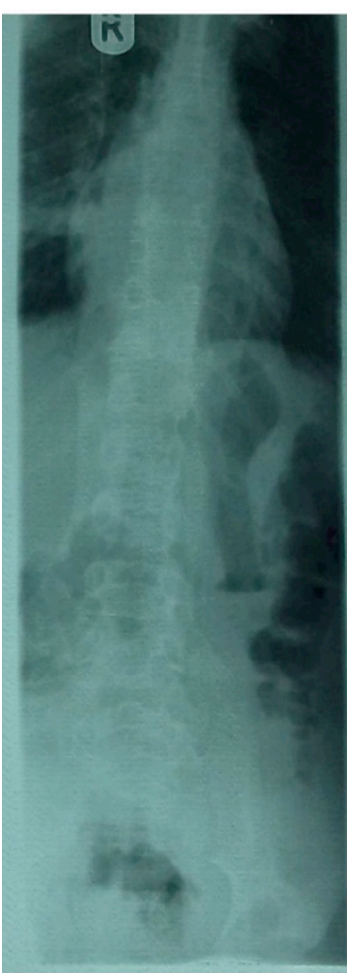

Figure 2A Paraspinal soft tissue ossification

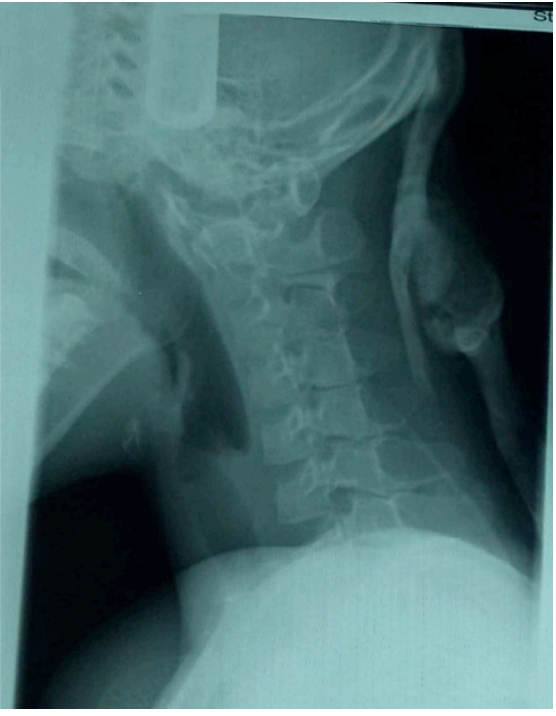

Figure 2B Extra skeletal soft tissue ossification in the neck
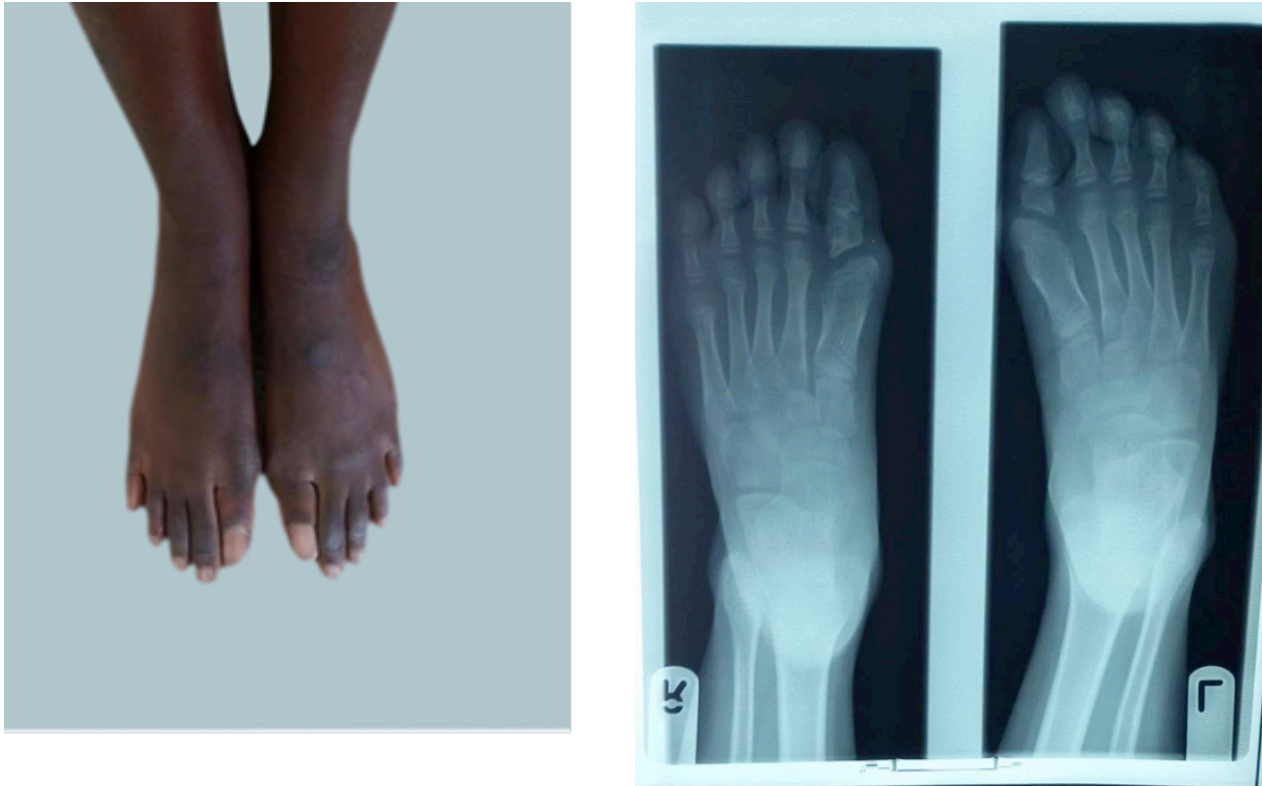

Figure 3 Hallux val-
Figure 4 Radiograph of Hallux valgus 
The family was advised against a biopsy or excision of the lesions. Analgesics and oral prednisolone were given for the period of the flare-up with resolution of the acute symptoms after three weeks and he is presently able to attend school regularly.

The patient and his parents were counseled regarding the cause, course and prognosis of the disease and the availability of support groups like the International Fibrodysplasia Ossificans Progressiva Association (IFOPA).

\section{DISCUSSION}

Fibrodysplasia ossificans progressiva (FOP) is a rare disease with peculiar phenotypic features of extraskeletal new bone formation and great toe abnormalities. It is unsurprising the diagnosis wasn't made in this patient until the fifth year after initial presentation.

A survey from five continents by Kitterman et al showed erroneous diagnoses in about $90 \%$ with $67 \%$ of patients being subjected to potentially harmful invasive diagnostic procedures. ${ }^{4,7-10}$ Awareness across a wide spectrum of practitioners is key to early diagnosis and prevention of injurious diagnostic or therapeutic interventions. Although it is a rare disease, the clinical features are unique and unambiguous and genetic testing has recently become available. ${ }^{2,5}$

A biopsy is contraindicated due to risk of catastrophic explosive new bone formation., ${ }^{2,11}$ Disease flare-ups may be precipitated by trauma including intramuscular injections, lesion biopsies and nerve blocks especially around the temporomandibular joint. ${ }^{4,10-13}$

There is presently no cure for the disease. A multitude of therapeutic agents have been tried without success but some selected agents like palovarotene currently undergoing clinical trials have shown some promise. ${ }^{14-16}$

Currently analgesia with non-steroidal antiinflammatory drugs and a short course of steroids started at the onset of a flare-up are the mainstay of treatment during "flare-ups." 2

Support groups such as IFOPA offer up to date advice and invaluable information concerning the disease.

\section{REFERENCES}

1. Illingworth RS: Myositis Ossificans Progressiva (Munchmeyer's disease): A brief review with report of two cases treated with corticosteroids and observed for 16 years: Archives of Disease in childhood. 1971:46, 264-68.
2. Pignolo JS, Shore EM, Kaplan FS: Fibrodysplasia Ossificans Progressiva: Clinical and genetic aspects. Orphanet Journal of Rare Disease, 2011, 6:80 doi: 1186/1750-1172-6-80.

3. Kaplan FS, Zasloff MA et al: Early Mortality and Cardiorespiratory failure in patients with fibrodysplasia Ossificans progressiva J Bone Joint Surg Am 2010, 92:686-91.

4. Kaplan FS et al. Early diagnosis of Fibrodysplasia Ossificans Progressiva. Pediatrics 2008; 121; el295. doi 10.1542/peds. 2007-1980.

5. Shore EM, Xu M, Feldman GJ, et al. A recurrent mutation in the BMP type 1 receptor ACVR1 causes inherited and sporadic fibrodysplasia Ossificans progressiva. Nat Genet. 2006; 38(5): 525-27.

6. Shore EM. Fibrodysplasia Ossificans progressiva (FOP): A human genetic disorder of extraskeletal bone formation, or - How does one tissue become another? Wiley interdiscip Rev Dev Biol. 2012 January - February; 1 (1): 153-65.

7. Hampton I, Ofori Amanfo G. A familial case of Fibrodysplasia Ossificans Progressiva (myositis ossificans progressive). Trop Doct. 1998 Apr;28(2): 108-9.

8. Yasuhara $\mathrm{N}$ et al: Deformity of the great toe in fibrodysplasia ossificans progressive. J. Orthop Science. 2010 Nov; 15(6): 804-9.

9. Kaplan FS, Tabas JA, Gannon FH, Finkel G, Hahn GV, Zasloff MA. The histopathology of fibrodysplasia ossificans progressive. An endochondral process. J Bone Surgery Am. 1993 Feb; 75(2): 220-30

10. Kitterman JA, Kantanie S, Rocke DM, Kaplan FS. Iatrogenic Harm Caused by Diagnostic Errors in Fibrodysplasia ossificans Progressiva. Paediatrics. 2005 November; 116 (5): 654-661.

11. Zan X, Wang J, You C: The danger of biopsy in fibrodysplasia Ossificans Progressiva. Arch Dis Child. 2012 Sep; 97 (9): 785-6.

12. Ishaq A, Sameer R, Aymen A: Fibrodysplasia Ossificans progressiva - Radiological findings: A case report. Oman Med J. Sep 2014; 29 (5): 368-370.

13. Hashemi J, Shahfarhat A, Beheshtian A: Fibrodysplasia Ossificans Progressiva: Report of a case and Review of Articles. Iran J. Radiol. Sep 2011; 8(2):113-17.

14. Anamarli $\mathrm{N}$ et al: Fibrodysplasia Ossificans Progressiva. Arq Neuropsiquiatr 2000:58 (2): 342-47.

15. Altschuler EL. Consideration of Rituximab for fibrodysplasia ossificans progressive. Med Hypotheses. 2004; 63(3): 407-8.

16. Chakkalakal SA, Uchibe K, Convente MR, Zhang D, Economides AN, Kaplan FS, Pacifici M, Iwamoto M, Shore EM. Palovarotene inhibits heterotopic ossification and maintains limb mobility and growth in mice with human ACVRR206H fibrodysplasia ossificans (FOP) mutation. J Bone Miner Res. 2016 Feb; doi.1002/jbmr.2820. 